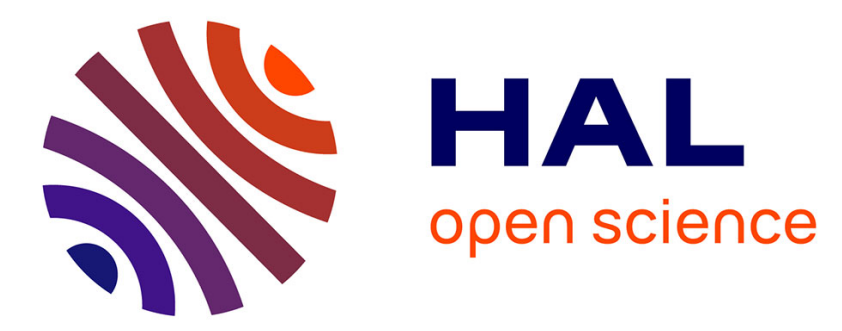

\title{
Liquid Processing of Bismuth-Silica \\ Nanoparticle/Aluminum Matrix Nanocomposites for Heat Storage Applications
}

Binghua Ma, Walid Baaziz, Léo Mazerolles, Ovidiu Ersen, Bernard Sahut, Clément Sanchez, Stéphane Delalande, David Portehault

\section{To cite this version:}

Binghua Ma, Walid Baaziz, Léo Mazerolles, Ovidiu Ersen, Bernard Sahut, et al.. Liquid Processing of Bismuth-Silica Nanoparticle/Aluminum Matrix Nanocomposites for Heat Storage Applications. ACS Applied Nano Materials, 2022, pp.10.1021/acsanm.1c03534. 10.1021/acsanm.1c03534 . hal03560991

\section{HAL Id: hal-03560991 \\ https://hal.science/hal-03560991}

Submitted on 7 Feb 2022

HAL is a multi-disciplinary open access archive for the deposit and dissemination of scientific research documents, whether they are published or not. The documents may come from teaching and research institutions in France or abroad, or from public or private research centers.
L'archive ouverte pluridisciplinaire HAL, est destinée au dépôt et à la diffusion de documents scientifiques de niveau recherche, publiés ou non, émanant des établissements d'enseignement et de recherche français ou étrangers, des laboratoires publics ou privés. 


\title{
Liquid Processing of Bismuth-Silica Nanoparticle/Aluminum Matrix Nanocomposites for Heat Storage Applications
}

\author{
Binghua Ma, Walid Baaziz, Léo Mazerolles, Ovidiu Ersen, Bernard Sahut, Clément Sanchez, \\ Stéphane Delalande, ${ }^{*}$ and David Portehault*
}

\begin{abstract}
Metal matrix nanocomposites encompassing low-melting point metal nano-inclusions are promising candidates for thermal regulation of devices at high temperature. They are usually processed by solid-state routes that provide access to a limited range of materials and are hardly compatible with complex shaping processes and with large-scale applications. Herein, we develop a liquid-phase processing technique to design aluminum matrix nanocomposites made of phase change nanoparticles, using bismuth nanoparticles as a proof-of-concept. The bismuth
\end{abstract}

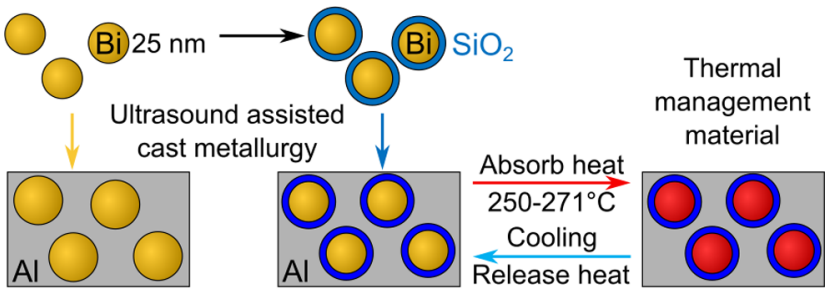

Bi-Al nanocomposite $\mathrm{Bi} @ \mathrm{SiO}_{2}$-Al nanocomposite nanoparticles derived from colloidal chemistry are first encapsu-

lated in a silica shell and then dispersed by ultrasonication into molten aluminum. Using X-ray diffraction, electron microscopy, and X-ray photoelectron spectroscopy, we probe the evolution of the bismuth particles and of the inorganic shell. We demonstrate that the silica shell acts as a barrier against extensive coalescence of particles during the dispersion process, thus enabling a decrease and a widening of the phase change temperature range.

aluminum, composites, nanoparticles, core-shell, bismuth, heat storage, phase change

\section{INTRODUCTION}

Phase change materials (PCMs) display a promising range of applications for thermal control of electronic devices ${ }^{1}$ and for flame retardants ${ }^{2-4}$ by absorbing and releasing heat upon melting and solidifying, respectively. Compared to air and liquid cooling or to heat pipes, PCMs use less power and require less complex thermal system design. ${ }^{5}$ Enhancing the heat management efficiency of PCMs and their response time requires a significant increase in their thermal conductivity. ${ }^{6}$ This aim can be reached by embedding phase change inclusions within metal matrices that are much more thermally conductive than common polymer matrices and also offer higher mechanical strength. ${ }^{6}$ The development of composites made of metallic PCM inclusions into metallic matrices would provide access to temperature ranges that are not accessible to organic PCMs, ${ }^{7}$ thus paving the way to other fields of applications, such as the automotive field. Using PCM metal or alloy nanoparticles and their related depression of melting point versus bulk materials would offer an additional degree of freedom by enabling to tune the phase change temperature (PCT) not only with the composition but also with the particle size. ${ }^{8}$ These metal matrix nanocomposites are, however, limited by their fabrication. To ensure dispersion of the inclusions, they are produced either by powder metallurgy 9,10 or by chemical synthesis of the matrix, ${ }^{8}$ which are not adapted to large-scale applications. ${ }^{9}$ Dispersion of PCM nanoscaled inclusions into metal matrices by liquid metallurgy would offer access to a wide range of materials with high versatility in the choice of the materials and of the PCT. It would also enable coupling with a variety of liquid-based shaping processes and would deliver materials relevant at the industrial scale. However, the targeted PCTs are usually below the melting point of the metal matrix. Therefore, producing metal matrix PCM nanocomposites by liquid metallurgy is a great challenge as it means dispersing liquid metal droplets in another liquid metal, at temperatures usually above $600{ }^{\circ} \mathrm{C}$, while avoiding coalescence of the PCM inclusions and/or alloying with the matrix. Melt spinning has been proposed to quench the coalescence of particles precipitated in the liquid phase by fast cooling when the matrix is an amorphous alloy. ${ }^{11}$ The method cannot be applied to bulk crystalline matrices. As a result, no crystalline metal matrix PCM composite, containing either nano- or micro-inclusions, has been reported from liquid metallurgy processes.

To address this challenge and enable liquid processing of metallic phase change nanocomposites, we propose to disperse colloidal chemistry-derived metal PCM nanoparticles in a 
molten metal by using ultrasonication ${ }^{12}$ in the melt at high temperatures (Figure 1, pathway A). To enhance the
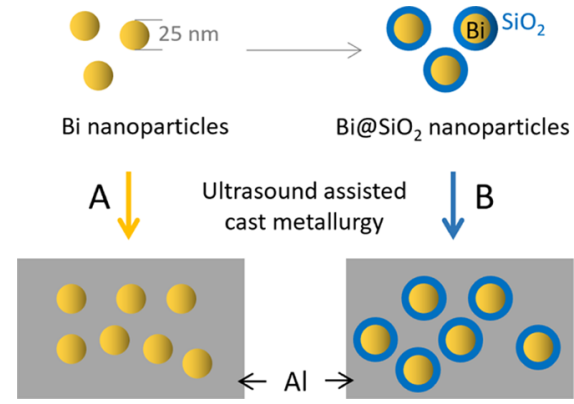

Figure 1. Scheme of the synthesis procedure for aluminum nanocomposites embedding $\mathrm{Bi}$ nanoparticles and $\mathrm{Bi} @ \mathrm{SiO}_{2}$ core@ shell nanoparticles. Pathways $\mathrm{A}$ and $\mathrm{B}$ correspond to the ultrasoundassisted incorporation of $\mathrm{Bi}$ and $\mathrm{Bi} @ \mathrm{SiO}_{2}$ nanoparticles, respectively.

dispersion and the stability over thermal cycling of the nanoparticles (Figure 1, pathway B), we encapsulate them in a silica shell prior to incorporation into the liquid metal. During incorporation, the shell is expected to react in situ with the metal matrix through the aluminothermal reduction. ${ }^{13} \mathrm{We}$ study herein the evolution of this shell, its impact on the nanostructure of the nanocomposites and on their phase change energy storage properties. We show that this procedure provides sustainable phase change properties over thermal cycling by maintaining the nanosize of the metal cores. We use bismuth nanoparticles as proof-of-concept phase change inclusions for their low-melting point and aluminum as a light weight, high thermal conductivity matrix.

\section{RESULTS AND DISCUSSION}

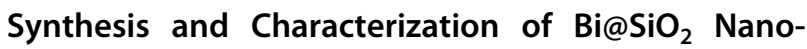

structures. We have prepared bismuth nanoparticles according to the colloidal synthesis proposed by Scheele et al. ${ }^{14}$ where bismuth acetate was reduced in oleylamine to form bismuth nanoparticles with 1-dodecanethiol ligands. X-ray diffraction (XRD) confirms (Figure S1) the formation of bismuth, and transmission electron microscopy (TEM) (Figure 2a) shows that the particles exhibit a narrow size distribution centered at around $25 \mathrm{~nm}$. In the second step, the bismuth nanoparticles were coated with a silica shell by adapting the Stöber method to ensure heterogeneous nucleation at the surface of the particles. ${ }^{15,16}$ TEM indicates a $7 \mathrm{~nm}$ thick shell with a contrast lower than the bismuth core (Figure $2 \mathrm{~b}$ ). The silica shell actually embeds several particles, forming aggregates with size up to $160 \mathrm{~nm}$. The dispersion state within the aggregates was quantified by the projected area distribution (Figure 2c), which shows that the silica shells embed from single to about 20 bismuth cores. Although significant aggregation is observed, the dispersion state is enhanced compared to previous methods using surfactants, ${ }^{17}$ instead of strongly bound thiol surface ligands.

To evaluate the efficiency of the silica shell in preventing coalescence of the bismuth cores, we have heated the coreshell nanostructures and sole bismuth nanoparticles above the melting point of bulk $\mathrm{Bi}\left(271^{\circ} \mathrm{C}\right)$. When heated at $320^{\circ} \mathrm{C}$, the bare $\mathrm{Bi}$ particles undergo extensive coalescence and growth (Figure S2). On the contrary, the general appearance of the $\mathrm{Bi} @ \mathrm{SiO}_{2}$ nanostructures was preserved at $350{ }^{\circ} \mathrm{C}$ (Figure $2 \mathrm{~d}$ ), and the size of the $\mathrm{Bi}$ cores only slightly increased for the cores
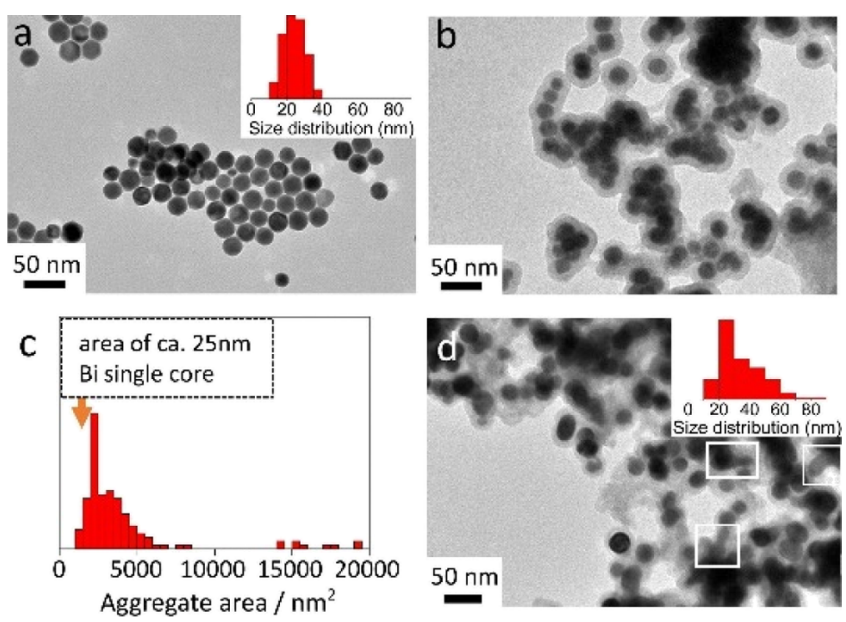

Figure 2. (a) TEM image and size distribution of Bi nanoparticles. (b) TEM image and (c) core projected area distribution of $\mathrm{Bi} @ \mathrm{SiO}_{2}$ nanostructures. (d) TEM image and size distribution of $\mathrm{Bi} @ \mathrm{SiO}_{2}$ nanostructures heated at $350{ }^{\circ} \mathrm{C}$. The white squares are showing areas where coalescence of the cores occurred within silica shells.

embedded in the same silica shell. Thus, the silica shell preserves the separated $\mathrm{Bi}$ cores from coalescence.

To provide additional information on coalescence during heating and cooling, in situ TEM experiments were carried out on $\mathrm{Bi} @ \mathrm{SiO}_{2}$ nanostructures by heating to $350{ }^{\circ} \mathrm{C}$ at $10{ }^{\circ} \mathrm{C}$ $\mathrm{min}^{-1}$. Scanning transmission electron microscopy-high-angle annular dark-field imaging (STEM-HAADF) images (Figure S3) show that the morphology of the nanoparticles was retained during heating and cooling, with a contrast revealing the clear edge of overlapped nanoparticles. The dependency of the coalescence behavior versus the aggregation state inside the silica shells has been further studied by in situ TEM (Figure S4). Above the melting point of $\mathrm{Bi}$ cores at around $250^{\circ} \mathrm{C}, \mathrm{Bi}$ cores embedded in the same silica shell and in contact with each other coalesce irreversibly (Figure S4, orange rectangle), while Bi cores initially separated with a silica layer from each other remain dispersed upon heating and cooling. Although $\mathrm{Bi}$ cores initially embedded together coalesce, they still remain trapped inside the shell over the melting point, thus making feasible the incorporation of $\mathrm{Bi} @ \mathrm{SiO}_{2}$ nanostructures into molten aluminum.

Bi@SiO 2 -Al Nanocomposites. Nanocomposites made of an aluminum matrix embedding $\mathrm{Bi} @ \mathrm{SiO}_{2}\left(\mathrm{Bi} @ \mathrm{SiO}_{2}-\mathrm{Al}\right)$ were synthesized by ultrasound-assisted liquid metallurgy. To ensure the full incorporation of the nanoparticles into molten aluminum, a pellet of $\mathrm{Bi} @ \mathrm{SiO}_{2}$ nanostructures $(0.25$ at \%) in aluminum was prepared by pressing $\mathrm{Bi} @ \mathrm{SiO}_{2}$ and aluminum powders pre-dispersed into ethanol (see details in the experimental method section). The pellet was then incorporated into molten aluminum at $740{ }^{\circ} \mathrm{C}$ by ultrasound treatment in an induction furnace. The resulting samples showed metallic aluminum appearance (Figure $\mathrm{S} 5$ ). The $\mathrm{Bi} / \mathrm{Al}$ ratio was evaluated by wavelength-dispersive X-ray fluorescence spectrometry (WDXRF) on the top and bottom of each sample and on middle slice cuts of the monoliths. The constant ratio of 0.3 at $\%$ in all pieces is consistent with the initial precursor ratio, indicating that all the nanostructures were incorporated and are homogeneously distributed into the whole volume of the monoliths.

Scanning electron microscopy (SEM) imaging in the backscattered electron mode (Figure 3a) highlights white 

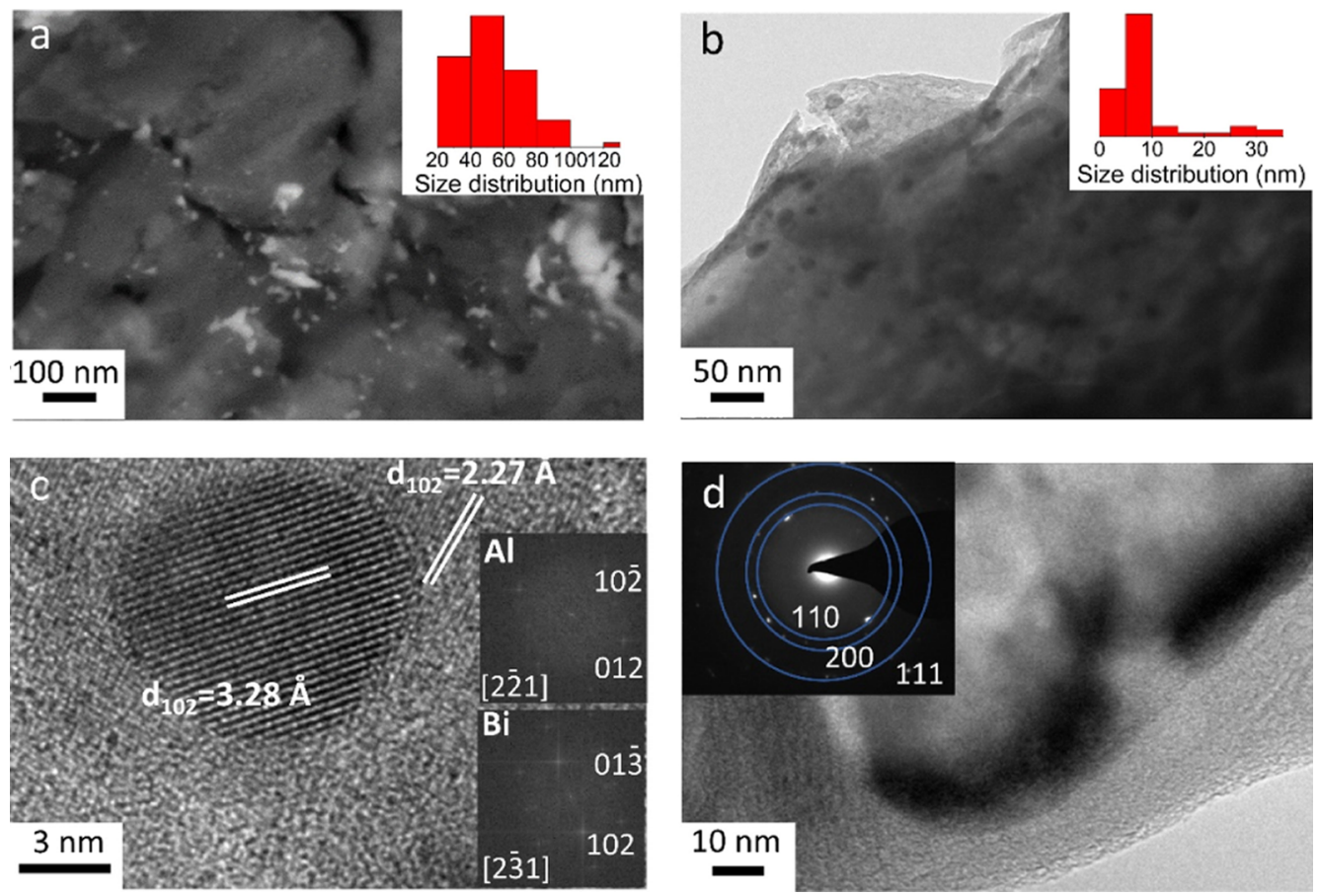

Figure 3. SEM and TEM study of a $\mathrm{Bi} @ \mathrm{SiO}_{2}-\mathrm{Al}$ nanocomposite. (a) Backscattered electron imaging-mode SEM image, bright and dark areas correspond to $\mathrm{Bi}$ and $\mathrm{Al}$ regions, respectively. ( $\mathrm{b}-\mathrm{d}$ ) TEM images. Dark and light contrasts correspond to $\mathrm{Bi}$ and $\mathrm{Al}$, respectively. Insets in ( $\mathrm{a}, \mathrm{b}$ ) show the corresponding size distributions. The inset in $(d)$ shows the SAED pattern corresponding to image (d) and indexed along the structure of bismuth.
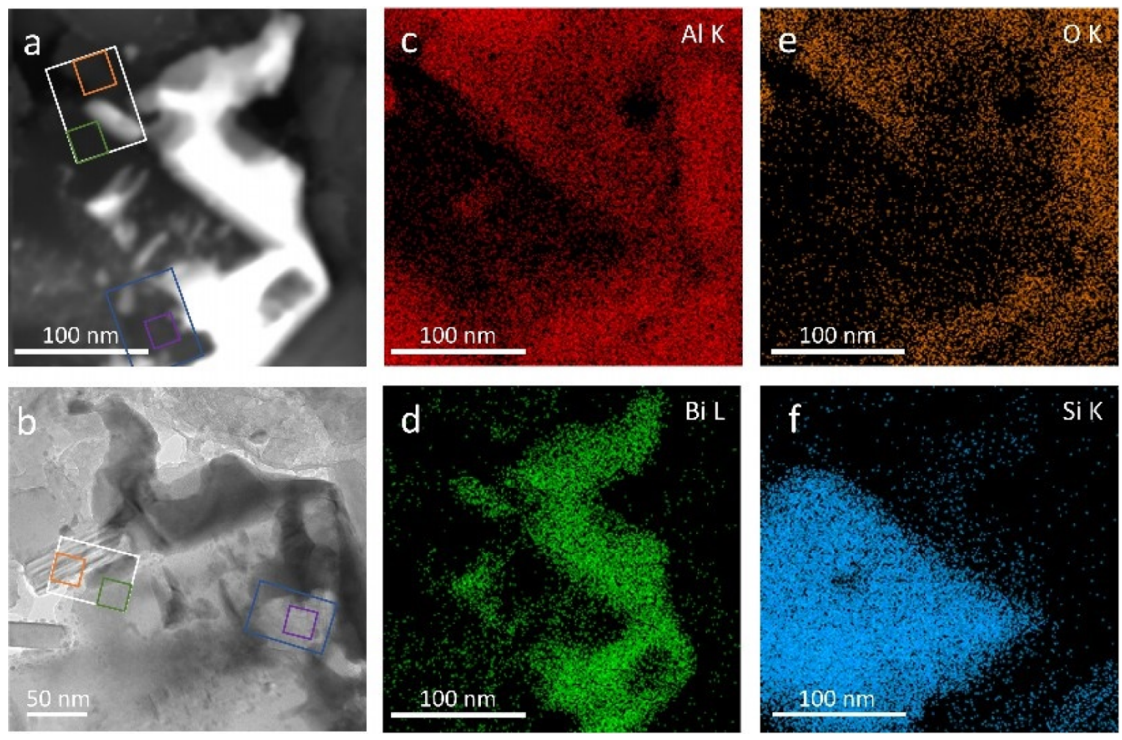

Figure 4. (a) STEM-HAADF, (b) STEM images, and corresponding (c-f) STEM-EDS maps of Bi@SiO $\mathrm{S}_{2}-\mathrm{Al}$ nanocomposites.

areas corresponding to electron-rich bismuth, with a size up to $120 \mathrm{~nm}$. The TEM images reveal $10 \mathrm{~nm}$ (Figure 3b,c) and 60 $\mathrm{nm}$ (Figure 3d) bismuth nanoparticles, well crystallized in the $\mathrm{Bi}$ hexagonal structure according to high-resolution TEM (HRTEM) (Figure 3c inset) and selected area electron diffraction (SAED) (Figure 3d inset) performed on the larger particles. HRTEM (Figure 3c) also highlights atomic planes of the $\mathrm{Al}$ matrix and does not indicate any intermediary phase between the matrix and the nanoparticles. Larger particles around $120 \mathrm{~nm}$ were also observed by STEM-HAADF (Figure S6). The size distributions evaluated by SEM and TEM highlight two distinct populations, centered, respectively, at ca. 60 and $8 \mathrm{~nm}$. According to TEM, particles below $10 \mathrm{~nm}$ were isotropic, while the shape of particles above $30 \mathrm{~nm}$ was irregular. Therefore, SEM and TEM evidence a widening of the size distribution from initial $25 \mathrm{~nm}$ Bi nanoparticles toward both smaller and larger particles. This behavior is indicative of Ostwald ripening during the incorporation process, a phenomenon in which bismuth from the smaller particles dissolve in the liquid medium and redeposit on larger particles. This hypothesis is supported by the slight but significant solubility of $\mathrm{Bi}$ in $\mathrm{Al}$ at $700{ }^{\circ} \mathrm{C}$ of about $1.5 \mathrm{wt} \% .{ }^{18}$ Note that sonication may also exacerbate Ostwald ripening, as already described on polymer composites. ${ }^{19,20}$ 
An area containing a large coalesced bismuth object was mapped by the STEM-energy-dispersive system (EDS) (Figure $4 \mathrm{a}-\mathrm{f}$ ). Bi was surrounded by an $\mathrm{O}$-rich area also containing $\mathrm{Al}$ but exempt of $\mathrm{Si}$ (orange square, Figure $4 \mathrm{a}$ ). This area corresponds (orange square, Figure $5 \mathrm{a}, \mathrm{b}$ ) to an $\mathrm{Al}$ /
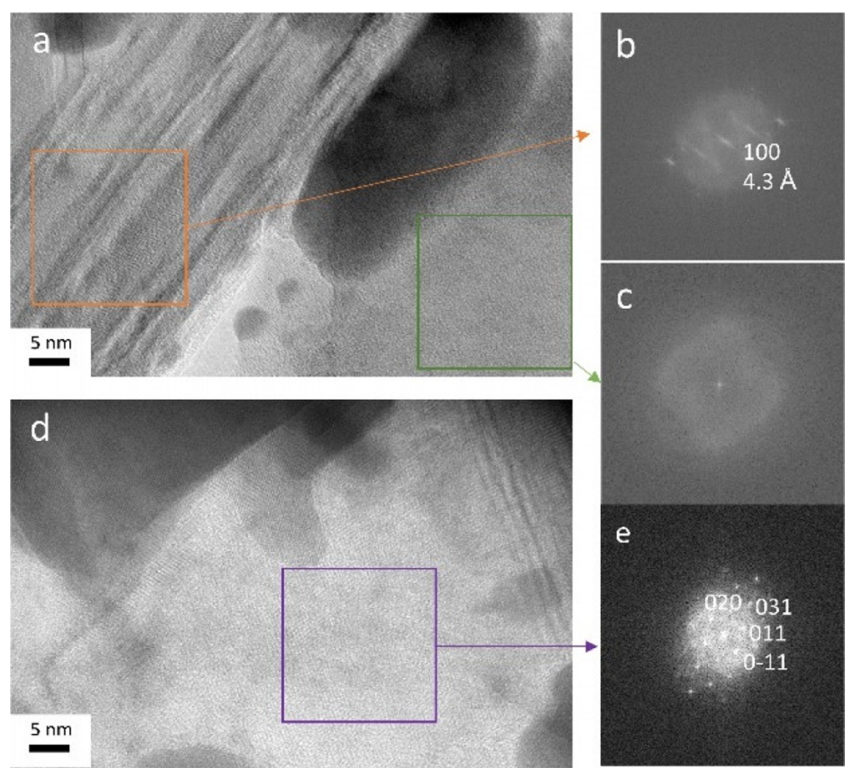

Figure 5. HRTEM study of the areas highlighted in Figure 4a,b by white, green, and violet squares. (a) HRTEM image acquired in the white rectangle in Figure 4a,b. (b,c) Fast Fourier transforms (FFTs) corresponding to the orange and green squares in (a) and in Figure $4 \mathrm{a}, \mathrm{b}$. The FFT in (b) for the $\mathrm{Al} / \mathrm{O}$-rich area is indexed along the structure of $\alpha-\mathrm{Al}_{2} \mathrm{O}_{3}$. The FFT in (c) for the Si-rich area shows an amorphous region. (d) HRTEM image shown in the blue rectangle in Figure 4a,b. (e) FFT of the violet area in (d), indexed along the structure of $\mathrm{Al}_{2} \mathrm{SiO}_{5}$.

O-rich rod-like region with non-uniform contrast, which highlights crystal defects. The interplanar distances measured by HRTEM are consistent with $\mathrm{Al}_{2} \mathrm{O}_{3}$ (100) planes. Therefore, bismuth is surrounded by alumina.

The Si map (Figure 4f) confirms that silicon was no longer around $\mathrm{Bi}$ particles and segregated into Bi-free areas (Figures 4 and $5 \mathrm{a}$ green square, $5 \mathrm{~d}$ violet square). The low overlap between Si-rich and O-rich regions (Figure 4f,e) indicates the formation of low oxidation state silicon species. We observed two types of regions in Si-rich area: an amorphous-like (Figure 5a green square and 5c) region and a crystalline region (Figures $5 \mathrm{~d}$ violet square and 5e). HRTEM analysis and the corresponding FFT of the crystalline part (Figure 5e) are fully consistent with the structure of sillimanite $\mathrm{Al}_{2} \mathrm{SiO}_{5}$. We discuss below the origin of these different components, which are indicative of the reaction mechanisms occurring during incorporation of the nanoparticles into the aluminum melt.

The presence of alumina, low oxidation state silicon species, and the aluminosilicate sillimanite is consistent with aluminothermic reduction of the silica shell of the $\mathrm{Bi} @ \mathrm{SiO}_{2}$ nanostructures, yielding aluminosilicates as reaction intermediates. ${ }^{13}$ In order to further confirm this reaction pathway, the redox processes involving the aluminum matrix and the silica shell were probed on a slice cut piece of nanocomposites analyzed by X-ray photoelectron spectroscopy (XPS) in the Si $2 \mathrm{p}$ (Figure 6a) and Si $2 \mathrm{~s}$ (Figure $6 \mathrm{~b}$ ) regions. The spectrum of pure aluminum was also recorded as a reference. The $\mathrm{Al}$
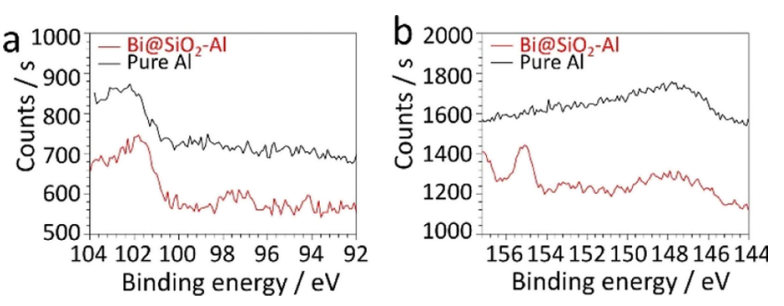

Figure 6. XPS analysis of $\mathrm{Bi} @ \mathrm{SiO}_{2}-\mathrm{Al}$ nanocomposites (red) and pure $\mathrm{Al}$ (black) at the (a) Si $2 \mathrm{p}$ and (b) Si 2 s areas.

plasmonic peak overlaps with the $\mathrm{Si} 2 \mathrm{p}$ binding energy regions between 99 and $102 \mathrm{eV}$ (Figure 6a), but the Si 2s area enables to decipher the $\mathrm{Al}$ plasmon peak at $147.4 \mathrm{eV}$ from the $\mathrm{Si} 2 \mathrm{~s}$ signal at about 150-155 eV (Figure 6b). For the $\mathrm{Bi} @ \mathrm{SiO}_{2}-\mathrm{Al}$ composite, the most intense peak at $155.1 \mathrm{eV}$ accounts for the $\mathrm{Si}-\mathrm{O}$ bonds of $\mathrm{SiO}_{2}{ }^{21}$ An additional contribution between 150 and $154 \mathrm{eV}$ is not observed for pure aluminum and is ascribed to other silicon species at lower binding energy than that for $\mathrm{SiO}_{2}$, which is consistent with low oxidation state $\mathrm{Si}$ species and/or an aluminosilicate. ${ }^{13}$ According to XPS and STEM-EDS (Figures 4a,b and 5), we assign the amorphous areas to low oxidation state silicon. Because oxidation of low oxidation state $\mathrm{Si}$ species could occur upon exposure to air during transfer of the sample to the XPS chamber, the pristine samples could exhibit a higher portion of reduced silicon than indicated by XPS analysis.

The reduction of $\mathrm{SiO}_{2}$ particles (about $30 \mu \mathrm{m}$ ) by molten aluminum has been studied by Deqing and Ziyuan. ${ }^{13}$ In the $\mathrm{Al}-\mathrm{SiO}_{2}$ system, the reduction of silica by aluminum is thermodynamically favorable (reaction 1 below). Once alumina is formed, it can react with remaining silica and then form mullite or other aluminosilicates (reaction 2), evolving finally toward alumina and silicon (reaction 3 ).

$$
\begin{aligned}
& 4 \mathrm{Al}+3 \mathrm{SiO}_{2} \rightarrow 2 \mathrm{Al}_{2} \mathrm{O}_{3}+3 \mathrm{Si} \\
& 3 \mathrm{Al}_{2} \mathrm{O}_{3}+2 \mathrm{SiO}_{2} \rightarrow \mathrm{Al}_{6} \mathrm{Si}_{2} \mathrm{O}_{13} \\
& 8 \mathrm{Al}+3 \mathrm{Al}_{6} \mathrm{Si}_{2} \mathrm{O}_{13} \rightarrow 13 \mathrm{Al}_{2} \mathrm{O}_{3}+6 \mathrm{Si}
\end{aligned}
$$

Deqing and Ziyuan ${ }^{13}$ also observed the formation of a $5 \mu \mathrm{m}$ thick shell of alumina surrounding unreacted $\sim 20 \mu \mathrm{m}$ silica particles after $30 \mathrm{~min}$ of reaction at 700 with $5{ }^{\circ} \mathrm{C} \mathrm{min} \mathrm{m}^{-1}$ heating rate, while silicon had migrated within the aluminum matrix and formed rod-like Si inclusions. In our study, the silica component is present in the silica shell with a thickness of 7 $\mathrm{nm}, 3$ orders of magnitude lower than previously studied, ${ }^{13}$ which supports the reduction of silica to a larger extent at a similar temperature. Nonetheless, aluminothermic reduction is not complete as we observe, besides amorphous low oxidation state silicon, an intermediate $\mathrm{Si}$ (IV)-containing aluminosilicate. This behavior can be attributed to short reaction times, as our experiments rely on induction heating at a rate of $350{ }^{\circ} \mathrm{C}$ $\mathrm{min}^{-1}$ and reaction time of $10 \mathrm{~min}$. We have observed the formation of sillimanite $\left(\mathrm{Al}_{2} \mathrm{SiO}_{5}\right)$ as the intermediate phase. Generally, sillimanite forms above $776{ }^{\circ} \mathrm{C},{ }^{22}$ corresponding to $40{ }^{\circ} \mathrm{C}$ over our synthesis temperature. This high-temperature phase may be induced by intense local heating provided by ultrasound treatment. ${ }^{23}$

Overall, we propose the following reaction mechanism: Bi nanoparticles were partially coalesced inside the silica shell during the heating ramp. The pristine silica shell was reduced by aluminum that is concomitantly oxidized and reacts with 

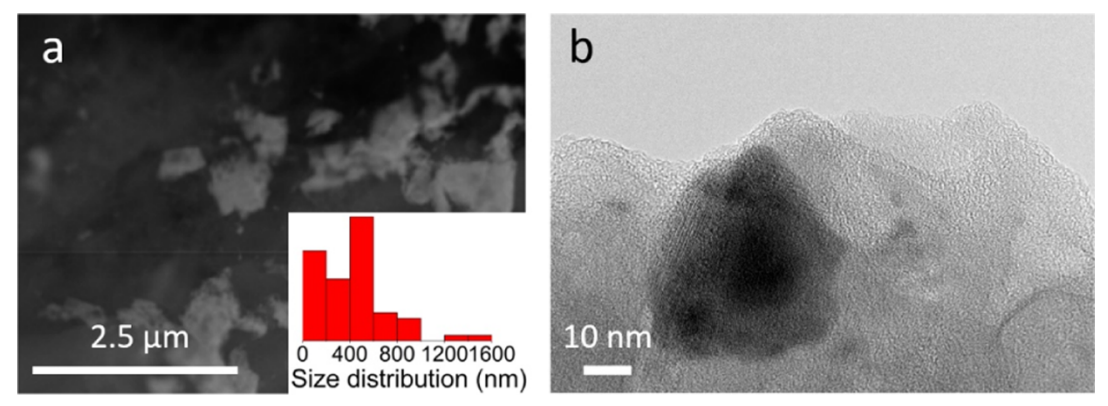

Figure 7. (a) SEM image and corresponding size distribution and (b) TEM image of a Bi-Al nanocomposite.

remaining silica to form an aluminosilicate intermediate. During ultrasound-assisted heating for the nanocomposite preparation, the silica shell separates from the Bi core, leading to a leaching of $\mathrm{Bi}$ droplets which then undergo Ostwald ripening and develop into two populations.

Bi-Al Nanocomposites. To probe the impact of the silica shell on the dispersion of $\mathrm{Bi}$ nano-objects, we have incorporated $\mathrm{Bi}$ nanoparticles without silica into molten aluminum, as described above for $\mathrm{Bi} @ \mathrm{SiO}_{2}-\mathrm{Al}$ composites. The as-obtained $\mathrm{Bi}-\mathrm{Al}$ composite exhibits also an evolution of $\mathrm{Bi}$ objects into two populations (Figure 7), one around one micrometer and another one around $5-30 \mathrm{~nm}$. Bismuth then underwent Ostwald ripening, as with the silica shell, but the population of large objects showed significantly larger size, losing the nanoscale, when no silica was used. Therefore, although the silica shell in $\mathrm{Bi} @ \mathrm{SiO}_{2}-\mathrm{Al}$ composites underwent chemical reaction and local mobilization, it acted efficiently against coalescence of the cores during incorporation into molten aluminum. Thus, the $\mathrm{Bi} @ \mathrm{SiO}_{2}-\mathrm{Al}$ nanocomposite exhibited a wide size distribution at the nanoscale.

Thermal Properties of Bismuth and $\mathrm{Bi@SiO}{ }_{2}$ Nanoparticles. Differential scanning calorimetry (DSC) was performed for both precursor $\mathrm{Bi}, \mathrm{Bi} @ \mathrm{SiO}_{2}$ nanoparticles, and the corresponding nanocomposites. Figure $8 \mathrm{a}, \mathrm{b}$ displays the
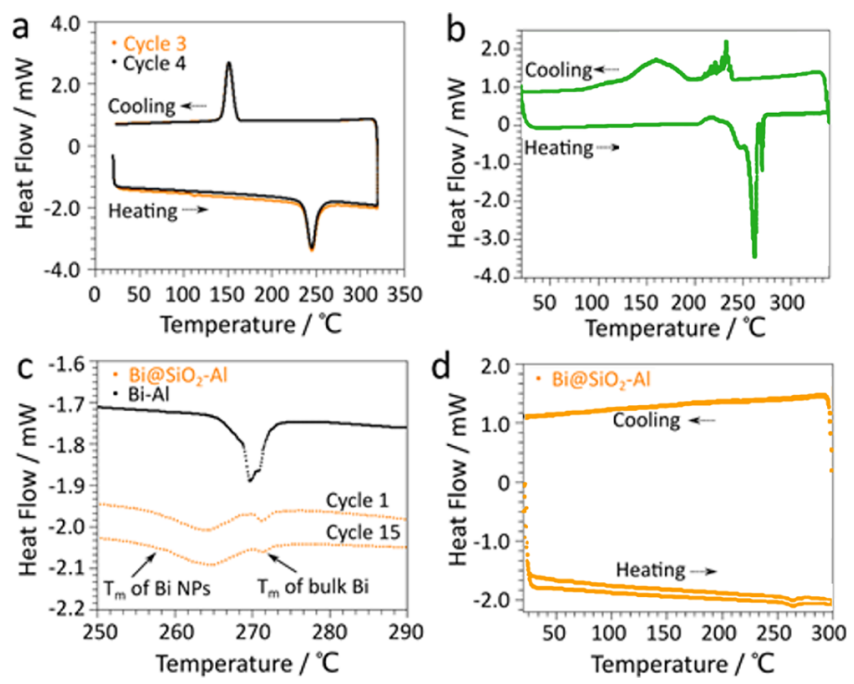

Figure 8. DSC analysis of (a) $\mathrm{Bi} @ \mathrm{SiO}_{2}$ during the third heatingcooling cycle and of (b) Bi nanoparticles (green). (c, d) DSC analysis of a $\mathrm{Bi} @ \mathrm{SiO}_{2}-\mathrm{Al}$ nanocomposite with (c) zoomed-in area at 250$290{ }^{\circ} \mathrm{C}$ during heating for the 1 st and 15 th cycles (orange). The DSC analysis of a reference $\mathrm{Bi}-\mathrm{Al}$ sample is also shown for the first heating ramp in (c) (black). thermal behavior at the third heating-cooling cycle for pristine $\mathrm{Bi} @ \mathrm{SiO}_{2}$ and $\mathrm{Bi}$ nanoparticles, respectively. $\mathrm{Bi} @ \mathrm{SiO}_{2}$ particles exhibit an endothermic peak at $\sim 242{ }^{\circ} \mathrm{C}$, which is in agreement with the depression of the melting point $\left(271{ }^{\circ} \mathrm{C}\right.$ for bulk $\mathrm{Bi}$ ) with particle size decrease. ${ }^{8}$ The melting point measured herein for $25 \mathrm{~nm}$ silica-coated $\mathrm{Bi}$ nanoparticles is in accordance with the results obtained for Bi-carbon nanocomposites. ${ }^{24} \mathrm{Bi} @ \mathrm{SiO}_{2}$ nanoparticles exhibit reversible thermal properties over four cycles (Figure 8a). On the contrary, the bare bismuth nanoparticles (Figure 8 b) display three sharp endothermic peaks at $\sim 263$ and $271{ }^{\circ} \mathrm{C}$, the latter corresponding to bulk $\mathrm{Bi}$ melting. The first two endothermic peaks are attributed to the melting temperature depression with the particle size. ${ }^{8}$ The appearance of the peaks at higher temperature indicate that the nanoparticles coalesced, and large particles up to bulk were formed. Therefore, the silica shell was necessary to maintaining the nanoscale and the melting point depression of $\mathrm{Bi}$ nanostructures. These results are consistent with TEM observations after heating (Figure $\mathrm{S} 2$ ).

Thermal Properties of Nanocomposites Encompassing Phase Change Bismuth Inclusions. The DSC curves for the $\mathrm{Bi} @ \mathrm{SiO}_{2}-\mathrm{Al}$ composites (Figure 8c,d) also show endothermic peaks during heating and an exothermic broad peak during cooling, indicating solidification of undercooled bismuth. The high-temperature region of the DSC curves (Figure 8c) shows that the melting behavior significantly differs from those of the initial particles described above. The $\mathrm{Bi} @ \mathrm{SiO}_{2}-\mathrm{Al}$ nanocomposite exhibits two endothermic peaks: a broad melting peak at $263{ }^{\circ} \mathrm{C}$ with the onset temperature at $251{ }^{\circ} \mathrm{C}$, corresponding to nanoparticles melting, and a low intensity sharper peak at $271{ }^{\circ} \mathrm{C}$, corresponding to bulk bismuth. The shift of these peaks to higher temperatures compared to unreacted $\mathrm{Bi} @ \mathrm{SiO}_{2}$ nanoparticles confirms that the nanoparticles coalesced during the incorporation of the particles into the melt, but a significant fraction still shows melting point depression, indicating that nanoscale objects have been maintained. This is consistent with the remaining single $\mathrm{Bi}$ nanoparticles or aggregates of only few $\mathrm{Bi}$ cores within the initial nanocomposite, as described above (Figures 3 and S6). The enthalpy ratio for the peaks at 263 and at $271{ }^{\circ} \mathrm{C}$ is 9:1, indicating that around $90 \%$ of $\mathrm{Bi}$ element are still nanoscaled, with the assumption that the melting latent heat of nanoscale $\mathrm{Bi}$ is close to the value for bulk $\mathrm{Bi}$. Because the melting latent heat decreases with the particle size, ${ }^{8}$ one can assume that the molar fraction of bismuth at the nanoscale is above $90 \%$. The heat absorption ability evaluated by the enthalpy of the melting process was $0.38 \mathrm{~J} \mathrm{~g}^{-1}$, close to the expected value based on the chemical composition at $0.47 \mathrm{~J} \mathrm{~g}^{-1}$ using the melting latent heat of bulk $\mathrm{Bi}$. DSC over 15 
consecutive heating-cooling cycles between 20 and $300{ }^{\circ} \mathrm{C}$ showed the cycling ability of the Bi core after melting as the DSC curves and the latent heat remained unchanged during cycling. The silicon species are considered stable after cycling as the aluminosilicate phases are stable, ${ }^{25}$ and no reaction is expected between $\mathrm{Al}$ and $\mathrm{Bi}^{26}$ on the one side and $\mathrm{Al}$ and $\mathrm{Si}^{27}$ on the other side. Besides, thermal cycling is performed at temperatures much lower than the preparation temperature in molten aluminum, so that any structural changes are unlikely.

The heat absorption ability of the as-prepared $\mathrm{Bi} @ \mathrm{SiO}_{2}-\mathrm{Al}$ nanocomposite is low compared to $\mathrm{Bi} @ \mathrm{Al}_{2} \mathrm{O}_{3}-\mathrm{Al}$ prepared by powder metallurgy ${ }^{28}$ because we used a low $\mathrm{Bi}$ content material as a proof-of-concept. The heat storage capacity may be improved by increasing the amount of inclusion particles within the matrix. We did not detect by DSC the phase change of small nanoparticles around $8 \mathrm{~nm}$ expected from TEM observations, which occurred at around $240{ }^{\circ} \mathrm{C}$ in an $\mathrm{Ag}$ matrix. ${ }^{8}$ This could be explained by the decreased enthalpy with the particle size $e^{14,29}$ or the low volume fraction of nanoparticles smaller than $10 \mathrm{~nm}$. DSC further confirms the efficient role of the silica shell to limit the coalescence of $\mathrm{Bi}$ nanoparticles since the $\mathrm{Bi}-\mathrm{Al}$ nanocomposite showed three endothermic peaks at 262, 269, and $271{ }^{\circ} \mathrm{C}$ overlapped together and shifted to higher temperature compared to the $\mathrm{Bi} @ \mathrm{SiO}_{2}-\mathrm{Al}$ nanocomposite, which implies the consecutive coalescence of nanoparticles into bulk objects during cycling.

Compared to a $\mathrm{Bi}-\mathrm{Al}$ composite prepared by powder metallurgy $^{10}$ at the same heating rate and with micron and nano-sized bismuth inclusions, the distribution of melting temperatures for $\mathrm{Bi} @ \mathrm{SiO}_{2}-\mathrm{Al}$ prepared by our liquid metallurgy process is broader and shifted to lower temperatures. This demonstrates a decreased $\mathrm{Bi}$ particle size achieved through nanoparticle encapsulation. The small initial nanoparticle size, the protective silica shell, the ultrasound treatment inducing disruption of $\mathrm{Bi}$ droplets, and the rapid thermal treatments by induction heating are keys to achieve small inclusion nanoparticles with a wide phase transition temperature range, which can be a considerable advantage to ensure progressive heat absorption over a wide temperature range.

\section{CONCLUSIONS}

We have developed an ultrasound-assisted liquid metallurgy process to phase change metal matrix nanocomposites, by encapsulating pre-made metal nanoparticles within a silica shell. This shell acts as a barrier against extensive coalescence of the metal cores, which are molten during the incorporation process. This process relies on preliminary synthesis of nanoparticles, which ensures the suitability of the method for the very wide range of metal and alloy nanomaterials accessible by rich colloid chemistry. Hence, we believe that the process opens the way to a wide diversity of lightweight aluminumbased phase change materials that could be shaped according to liquid metal processing. Therefore, various fields of application can be targeted, including thermal regulation in automobiles. We also expect the mechanical properties of the resulting nanocomposites to be influenced by phase change inclusions. This point will be addressed in the future.

\section{EXPERIMENTAL METHODS}

Materials. Bismuth acetate (99.99\%), oleylamine (technical grade, $70 \%)$, 1-dodenanethiol (98\%), tetraethyl orthosilicate (TEOS, $99.99 \%)$, ammonia aqueous solution (28-30\%), and aluminum powder (99.99\%, 320 mesh) were all purchased from Sigma-Aldrich. Aluminum beads (99.9\%, around $3 \mathrm{~mm}$ diameter) were obtained from Alfa Aesar. The reagents were used as received.

Synthesis of Bismuth Nanoparticles and Silica-Coated Bismuth Nanoparticles. Bismuth nanoparticles were prepared by colloidal synthesis in a mixture of organic solvents based on a previous published protocol. ${ }^{14}$ Bismuth acetate $(1 \mathrm{mmol})$ was mixed with 1 dodecanethiol $(11.1 \mathrm{~mL})$ and heated to $45{ }^{\circ} \mathrm{C}$ for $45 \mathrm{~min}$ under vacuum. The reaction flask was purged with $\mathrm{N}_{2}$ and heated to $60{ }^{\circ} \mathrm{C}$. Oleylamine $(22.2 \mathrm{~mL})$ at room temperature was quickly added under stirring, and the reaction mixture was further heated for $24 \mathrm{~h}$. Finally, Bi nanoparticles were washed two times by ethanol/chloroform (20/1 $\mathrm{vol} / \mathrm{vol}$ ) and re-dispersed in ethanol. The silica-coated bismuth nanoparticles were prepared according to the Stöber method as follows: 15 TEOS was dissolved in absolute ethanol at a concentration of $0.38 \mathrm{M} .10 \mu \mathrm{L}$ of TEOS solution and $100 \mu \mathrm{L}$ of ammonia $30 \%$ were subsequently added to the $1 \mathrm{~mL}$ of alcoholic bismuth suspension [Bi] $=6 \times 10^{-4} \mathrm{M}$ under vigorous stirring. The mixture was heated at 40 ${ }^{\circ} \mathrm{C}$ for $3 \mathrm{~h}$ followed by washing by two cycles of centrifugationredispersion in ethanol. The final powder was dried in a vacuum oven at $40{ }^{\circ} \mathrm{C}$ for $16 \mathrm{~h}$. In order to evaluate the thermal stability, $20 \mathrm{mg}$ of $\mathrm{Bi} @ \mathrm{SiO}_{2}$ nanoparticles was annealed in a Naberthem chamber furnace under air condition for $1 \mathrm{~h}$ dwell time with a heating rate of $10{ }^{\circ} \mathrm{C} \mathrm{min}^{-1}$.

Synthesis of $\mathrm{Bi}-\mathrm{Al}$ and $\mathrm{Bi} @ \mathrm{SiO}_{2}$ Nanocomposites. $\mathrm{Bi}-\mathrm{Al}$ nanocomposites were prepared by ultrasound-assisted casting of a mixture composed of nanoparticles and aluminum in an induction oven. Briefly, $2 \mathrm{~g}$ of aluminum powders and alcoholic bismuth suspension were mixed by sonication at the boiling point for $1 \mathrm{~h}$ to get a ratio of 0.3 at $\%$ between $\mathrm{Bi}$ and $\mathrm{Al}$. Then, the mixture was dried in a vacuum oven at $40{ }^{\circ} \mathrm{C}$ for $1 \mathrm{~h}$, followed by pressing into a $13 \mathrm{~mm}$ pellet under 8 tons for $2 \mathrm{~min}$. Subsequently, the pellet and $0.4 \mathrm{~g}$ of pure $\mathrm{Al}$ beads were heated into an alumina crucible using an induction oven (CEIA, power cube 90 series 200) at $740{ }^{\circ} \mathrm{C}$ under an argon atmosphere. After dwelling for $1 \mathrm{~min}$, an ultrasound power of 80 Watts (QSonica, Q500A-220, USA) was applied through a sonication horn (niobium tip with $4 \mathrm{~mm}$ diameter) to disperse the nanoparticles for $5 \mathrm{~min}$. The final composite was obtained by cooling the melt in the crucible. It was then cut with a diamond wire saw for further analyses.

X-ray Diffraction. XRD was performed with a D8 Bruker diffractometer operating at the $\mathrm{Cu} \mathrm{K} \alpha$ radiation in the Bragg Brentano configuration. The ICSD reference 64709 was used for the indexation of bismuth nanoparticles.

Electron Microscopy. The cut pieces of the samples were observed with SEM (Hitachi SU-70 microscope) equipped with an Oxford X-Max $50 \mathrm{~mm}^{2}$ EDS detector. For preparation, the samples were mounted in polyfast resin (Struers), followed by a series of polishing steps through 1000, 2400, and 4800 grit papers (Buchler) and then with 3 and $1 \mu \mathrm{m}$ diamond suspensions. For the observation of nanoparticles in TEM, the nanoparticles were dispersed in ethanol, and then, a drop was evaporated on a carbon-coated copper grid. For the composites, TEM thin films were prepared by a parallelepiped rectangle of $3 \times 3 \times 0.5 \mathrm{~mm}$ cut in the middle of the sample. Polishing was then performed with a diamond disk to get a $200 \mu \mathrm{m}$ thick sample. The thickness of the center of the slab was further reduced to $50 \mu \mathrm{m}$ using a precision dimpling instrument (model 515, South Bay Technology). Ion milling was performed for the final thinning. TEM images were recorded on a Tecnai spirit G2 microscope operating at $120 \mathrm{kV}$. The STEM images and STEMEDX mapping were recorded with a JEM 2100Plus UHR microscope and a Tecnai F20 that were both operating at $200 \mathrm{kV}$. The size distribution of precursor nanoparticles was determined by counting 150-200 nanoparticles from TEM images. The size distribution of nanoparticles in the final nanocomposites was determined by counting 70-120 particles, from SEM images and TEM images, respectively. The ICDD 00380471 was used for the indexation of $\mathrm{AlSi}_{2} \mathrm{O}_{5}$.

Chemical Analysis by Wavelength-Dispersive X-ray Fluorescence Spectrometry. WDXRF spectroscopy was performed on 
the cut pieces of the samples with a Bruker S8 Tiger spectrometer equipped with a $\mathrm{Rh}$ tube.

Differential Scanning Calorimetry. DSC analysis was performed in a TA Q20 DSC instrument. Around $10 \mathrm{mg}$ of nanoparticles was sealed in an aluminum crucible. In the case of nanocomposites, top, middle, and bottom slices of the samples (around $40 \mathrm{mg}$ ) were analyzed separately to assess the homogeneity of the cast samples. To study the phase transition, the samples were heated to $320{ }^{\circ} \mathrm{C}$ and then cooled to $20^{\circ} \mathrm{C}$ with a slope of $10{ }^{\circ} \mathrm{C} \mathrm{min}-1$ followed by $3 \mathrm{~min}$ of stabilization at $20^{\circ} \mathrm{C}$ between each cycle. For each sample, at least three cycles were performed.

In Situ TEM. The experiments were carried out using a JEOL JEM$2100 \mathrm{~F}$ microscope operated at $200 \mathrm{kV}$ equipped with a spherical aberration probe corrector (Cs from CEOS), high-resolution objective lens pole piece, and an UltraScan 1000 CCD array detector (GATAN). For in situ observations, a Protochips Atmosphere system was used. The samples were suspended between two micro-electromechanical system-based closed cells made up of transparent $\mathrm{SiN}_{x}$ (for observation) and $\mathrm{SiC}$ (for heating). The in situ observations were carried out at a pressure of $1 \mathrm{~atm}$ under $\mathrm{Ar}$ at a flow rate of $0.1 \mathrm{~mL}$ $\mathrm{min}^{-1}$. The system was previously purged during few hours with the argon environment to ensure the proper cleaning of the gas lines and the sample holder.

\section{AUTHOR INFORMATION}

\section{Corresponding Authors}

Stéphane Delalande - Stellantis, Centre Technique de Vélizy, route de Gisy, Vélizy-Villacoublay 78140, France;

Email: stephane.delalande@stellantis.com

David Portehault - Sorbonne Université, CNRS, College de France, Laboratoire de Chimie de la Matière Condensée de Paris (LCMCP), F-75005 Paris, France; ๑ orcid.org/00000003-4914-4913; Email: david.portehault@sorbonneuniversite.fr

\section{Authors}

Binghua Ma - Sorbonne Université, CNRS, College de France, Laboratoire de Chimie de la Matière Condensée de Paris (LCMCP), F-75005 Paris, France; Stellantis, Centre Technique de Vélizy, route de Gisy, Vélizy-Villacoublay 78140, France

Walid Baaziz - Université de Strasbourg, CNRS, Institut de Physique et Chimie des Matériaux de Strasbourg (IPCMS), 67034 Strasbourg cedex 2, France

Léo Mazerolles - Université Paris Est, CNRS, Institut de Chimie et des Matériaux Paris-Est (ICMPE), 94320 Thiais, France

Ovidiu Ersen - Université de Strasbourg, CNRS, Institut de Physique et Chimie des Matériaux de Strasbourg (IPCMS), 67034 Strasbourg cedex 2, France; 10 orcid.org/0000-00021553-0915

Bernard Sahut - Stellantis, Centre Technique de Vélizy, route de Gisy, Vélizy-Villacoublay 78140, France

Clément Sanchez - Sorbonne Université, CNRS, College de France, Laboratoire de Chimie de la Matière Condensée de
Paris (LCMCP), F-75005 Paris, France; ๑ orcid.org/00000002-6426-4844

\section{Author Contributions}

B.M., D.P., B.S., S.D., and C.S. conceived the concept. B.M. performed synthesis, fabrication, and SEM and EDS characterization. L.M. prepared the TEM samples. W.B. and O.E. performed in situ TEM experiments. D.P. and S.D. supervised the project.

\section{ACKNOWLEDGMENTS}

The authors would like to thank for the funding by Stellantis and ANRT and the framework of the OpenLab $\beta \chi \Phi$ involving Stellantis and Sorbonne University. We thank the Institut des Matériaux de Paris Centre (IMPC FR2482) for servicing FEGSEM, EDX and XPS measurements (David Montero, Antoine Miche), Laboratoire de Réactivité de Surface (UMR 7197) for servicing TEM (Patricia Beaunier), and Sorbonne Université, CNRS, and C'Nano projects of the Region Ile-de-France for funding.

\section{REFERENCES}

(1) Wu, M.-S.; Liu, K. H.; Wang, Y.-Y.; Wan, C.-C. Heat Dissipation Design for Lithium-Ion Batteries. J. Power Sources 2002, 109, 160166.

(2) Qu, Z. G.; Li, W. Q.; Tao, W. Q. Numerical Model of the Passive Thermal Management System for High-Power Lithium Ion Battery by Using Porous Metal Foam Saturated with Phase Change Material. Int. J. Hydrogen Energy 2014, 39, 3904-3913.

(3) Alipanah, M.; Li, X. Numerical Studies of Lithium-Ion Battery Thermal Management Systems Using Phase Change Materials and Metal Foams. Int. J. Heat Mass Transfer 2016, 102, 1159-1168.

(4) Wu, W.; Yang, X.; Zhang, G.; Ke, X.; Wang, Z.; Situ, W.; Li, X.; Zhang, J. An Experimental Study of Thermal Management System Using Copper Mesh-Enhanced Composite Phase Change Materials for Power Battery Pack. Energy 2016, 113, 909-916.

(5) Offer, G.; Patel, Y.; Hales, A.; Diaz, L. B.; Marzook, M. Cool Metric for Lithium-Ion Batteries Could Spur Progress. Nature 2020, 582, 485-487.

(6) Jaguemont, J.; Omar, N.; Van den Bossche, P.; Mierlo, J. PhaseChange Materials (PCM) for Automotive Applications: A Review. Appl. Therm. Eng. 2018, 132, 308-320.

(7) Shchukina, E. M.; Graham, M.; Zheng, Z.; Shchukin, D. G. Nanoencapsulation of Phase Change Materials for Advanced Thermal Energy Storage Systems. Chem. Soc. Rev. 2018, 47, 4156-4175.

(8) Liu, M.; Ma, Y.; Wu, H.; Wang, R. Y. Metal Matrix-Metal Nanoparticle Composites with Tunable Melting Temperature and High Thermal Conductivity for Phase-Change Thermal Storage. ACS Nano 2015, 9, 1341-1351.

(9) Estruga, M.; Chen, L.; Choi, H.; Li, X.; Jin, S. UltrasonicAssisted Synthesis of Surface-Clean $\mathrm{TiB}_{2}$ Nanoparticles and Their Improved Dispersion and Capture in al-Matrix Nanocomposites. ACS Appl. Mater. Interfaces 2013, 5, 8813-8819.

(10) Abraham, A.; Schoenitz, M.; Dreizin, E. L. Energy Storage Materials with Oxide-Encapsulated Inclusions of Low Melting Metal. Acta Mater. 2016, 107, 254-260.

(11) Goswami, R.; Chattopadhyay, K. Depression of Melting Point of Multidomained Bismuth in Aluminum Based Metallic Glass Nanocomposites. Appl. Phys. Lett. 1996, 69, 910-912.

(12) Mohanty, P.; Mahapatra, R.; Padhi, P.; Ramana, C. V. V.; Mishra, D. K. Ultrasonic Cavitation: An Approach to Synthesize 
Uniformly Dispersed Metal Matrix Nanocomposites-A Review. Nano-Struct. Nano-Objects 2020, 23, 100475.

(13) Deqing, W.; Ziyuan, S. Aluminothermic Reduction of Silica for the Synthesis of Alumina-Aluminum-Silicon Composite. J. Mater. Synth. Process. 2001, 9, 241-246.

(14) Scheele, M.; Oeschler, N.; Meier, K.; Kornowski, A.; Klinke, C.; Weller, H. Synthesis and Thermoelectric Characterization of $\mathrm{Bi}_{2} \mathrm{Te}_{3}$ Nanoparticles. Adv. Funct. Mater. 2009, 19, 3476-3483.

(15) Wang, J.; Shah, Z. H.; Zhang, S.; Lu, R. Silica-Based Nanocomposites via Reverse Microemulsions: Classifications, Preparations, and Applications. Nanoscale 2014, 6, 4418-4437.

(16) Stöber, W.; Fink, A.; Bohn, E. Controlled Growth of Monodisperse Silica Spheres in the Micron Size Range. J. Colloid Interface Sci. 1968, 26, 62-69.

(17) Zhao, H.; Wang, J.; Li, X.; Li, Y.; Li, C.; Wang, X.; Wang, J.; Guan, S.; Xu, Y.; Deng, G.; Chen, Y.; Lu, J.; Liu, X. A Biocompatible Theranostic Agent Based on Stable Bismuth Nanoparticles for X-Ray Computed Tomography/Magnetic Resonance Imaging-Guided Enhanced Chemo/Photothermal/Chemodynamic Therapy for Tumours. J. Colloid Interface Sci. 2021, 604, 80-90.

(18) Manasijević, D.; Minić, D.; Balanović, L.; Premović, M.; Gorgievski, M.; Živković, D.; Milisavljević, D. Experimental Investigation and Thermodynamic Prediction of the $\mathrm{Al}-\mathrm{Bi}-\mathrm{In}$ Phase Diagram. J. Alloys Compd. 2016, 687, 969-975.

(19) Thompson, J. A.; Chapman, K. W.; Koros, W. J.; Jones, C. W.; Nair, S. Sonication-Induced Ostwald Ripening of ZIF-8 Nanoparticles and Formation of ZIF-8/Polymer Composite Membranes. Microporous Mesoporous Mater. 2012, 158, 292-299.

(20) Dirix, Y.; Bastiaansen, C.; Caseri, W.; Smith, P. Preparation, Structure and Properties of Uniaxially Oriented Polyethylene-Silver Nanocomposites. J. Mater. Sci. 1999, 34, 3859-3866.

(21) Barr, T. L. An XPS Study of Si as It Occurs in Adsorbents, Catalysts, and Thin Films. Appl. Surf. Sci. 1983, 15, 1-35.

(22) Salje, E. Heat Capacities and Entropies of Andalusite and Sillimanite: The Influence of Fibrolitization on the Phase Diagram of the $\mathrm{Al}_{2} \mathrm{SiO}_{5}$ Polymorphs. Am. Mineral. 1986, 71, 1366-1371.

(23) Suslick, K. S.; Didenko, Y.; Fang, M. M.; Hyeon, T.; Kolbeck, K. J.; McNamara, W. B.; Mdleleni, M. M.; Wong, M. Acoustic Cavitation and Its Chemical Consequences. Philos. Trans. R. Soc. London 1999, 357, 335-353.

(24) Tran, N.; Zhao, W.; Carlson, F.; Davidson, J. H.; Stein, A. Metal Nanoparticle - Carbon Matrix Composites with Tunable Melting Temperature as Phase-Change Materials for Thermal Energy Storage. ACS Appl. Nano Mater. 2018, 1, 1894-1903.

(25) Althaus, E. The Triple Point Andalusite - Sillimanite Kyanite. Contrib. Mineral. Petrol. 1967, 16, 29-44.

(26) Medraj, A. M. Binary Phase Diagrams and Thermodynamic Properties of Silicon and Essential Doping Elements (Al, As, B, Bi, Ga, In, N, P, Sb and Tl). Materials 2017, 10, 676.

(27) Haghshenas, M.; Jamali, J. Assessment of Circumferential Cracks in Hypereutectic Al-Si Clutch Housings. Case Stud. Eng. Fail. Anal. 2017, 8, 11-20.

(28) Khan, Z.; Khan, Z.; Ghafoor, A. A Review of Performance Enhancement of PCM Based Latent Heat Storage System within the Context of Materials, Thermal Stability and Compatibility. Energy Convers. Manage. 2016, 115, 132-158.

(29) Fu, Q.; Zhu, J.; Xue, Y.; Cui, Z. Size- and Shape-Dependent Melting Enthalpy and Entropy of Nanoparticles. J. Mater. Sci. 2017, 52, 1911-1918. 


\section{Supporting information}

\section{Liquid Processing of Bismuth-Silica}

Nanoparticle/Aluminum Matrix Nanocomposites for Heat Storage Applications

Binghua Ma, ${ }^{1,2}$ Walid Baaziz, ${ }^{3}$ Léo Mazerolles, ${ }^{4}$ Ovidiu Ersen, ${ }^{3}$ Bernard Sahut, ${ }^{2}$ Clément Sanchez, ${ }^{1}$ Stéphane Delalande, ${ }^{2 *}$ David Portehault ${ }^{1 *}$

${ }^{1}$ Sorbonne Université, CNRS, Collège de France, Laboratoire de Chimie de la Matière Condensée de Paris (LCMCP), 4 place Jussieu, F-75005, Paris, France

${ }^{2}$ Stellantis, Centre Technique de Vélizy, route de Gisy, Vélizy-Villacoublay, 78140, France

${ }^{3}$ Université de Strasbourg, CNRS, Institut de Physique et Chimie des Matériaux de Strasbourg (IPCMS), 23 rue du Lœss BP 43, 67034 Strasbourg cedex 2, France

${ }^{4}$ Université Paris Est, CNRS, Institut de Chimie et des Matériaux Paris-Est (ICMPE), 2-8 rue H. Dunant, 94320, Thiais, France

*Corresponding authors:

david.portehault@sorbonne-universite.fr

stephane.delalande@stellantis.com 


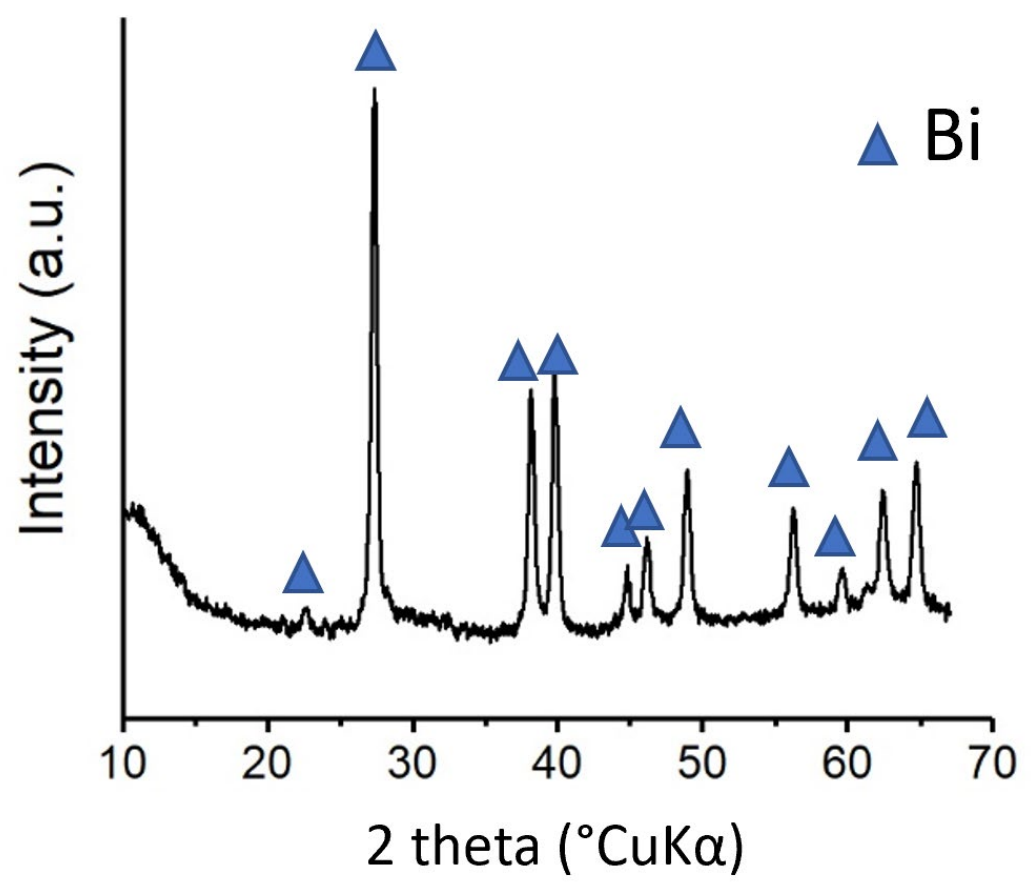

Figure S1. Powder XRD pattern of Bi nanoparticles.

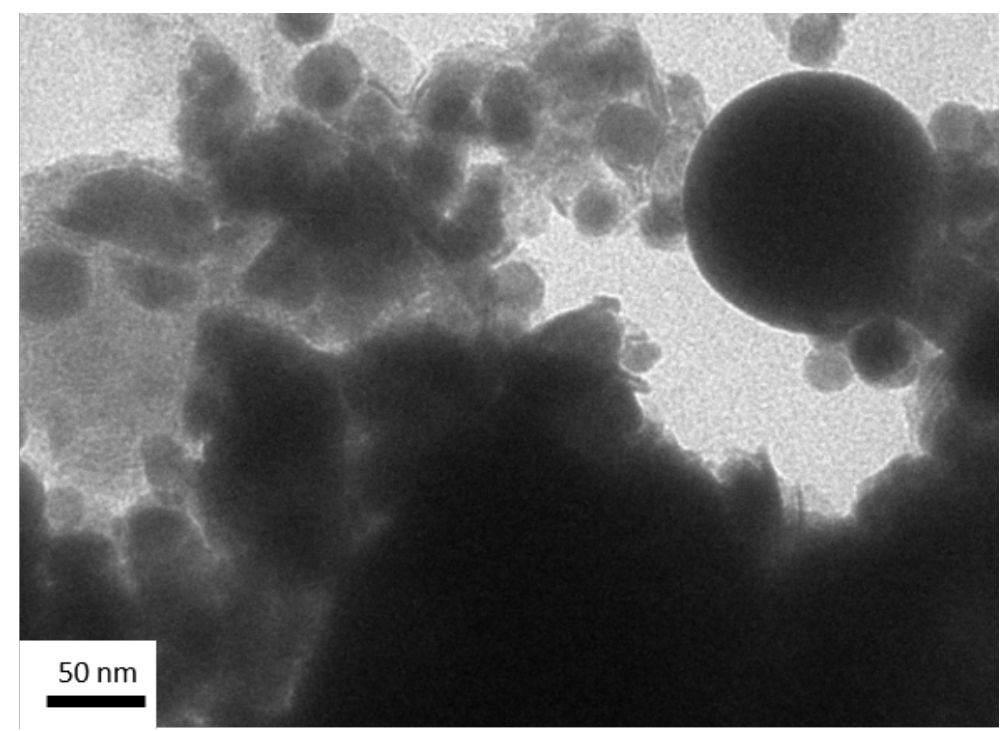

Figure S2. TEM image of bare Bi nanoparticles heated to $320^{\circ} \mathrm{C}$ after DSC cycling. 

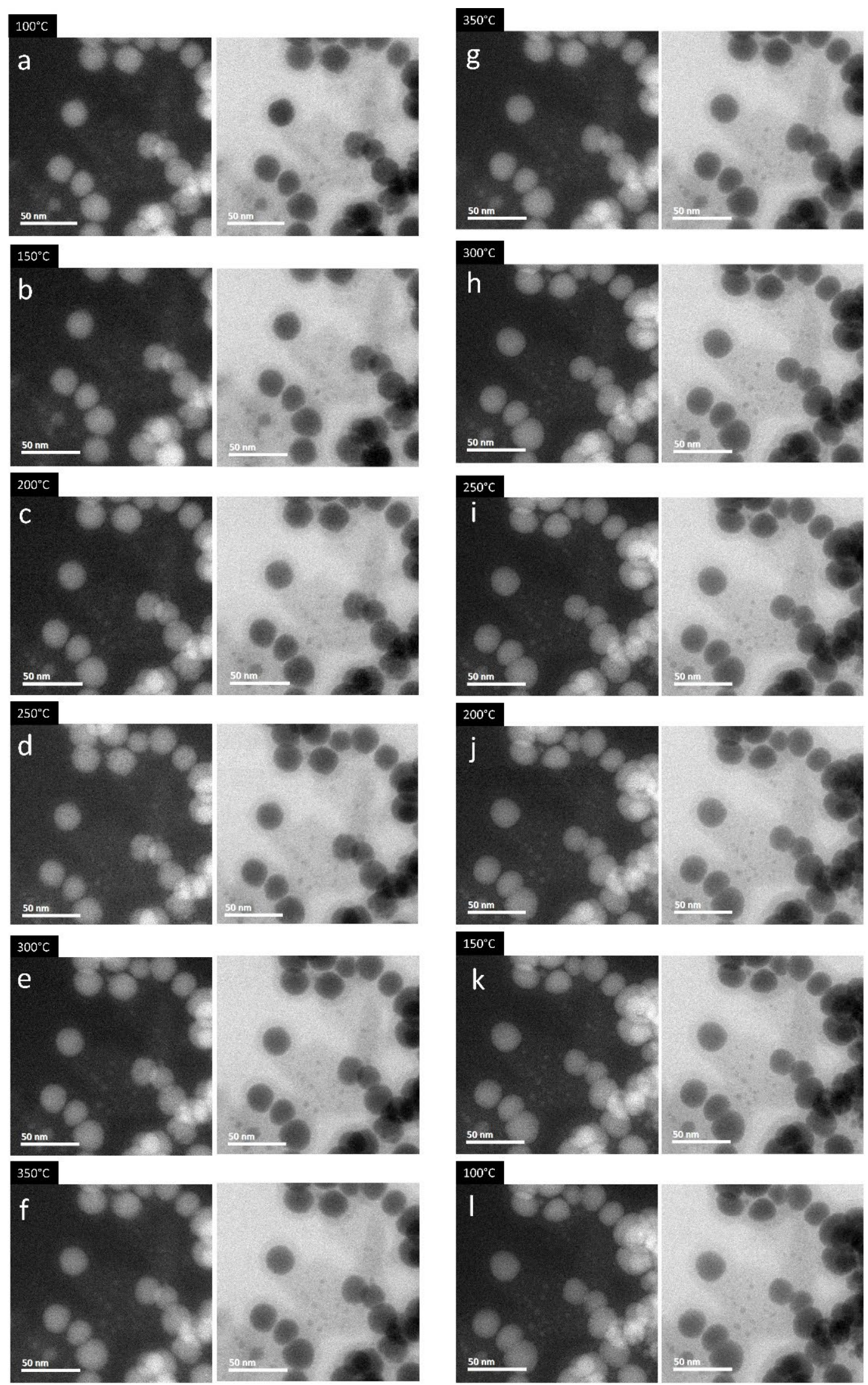

Figure S3. In situ STEM-HAADF and corresponding bright field STEM images of Bi@SiO nanostructures during heating from 100 to $350{ }^{\circ} \mathrm{C}$ (left column) and cooling down (right column) under 760 Torr of argon at $10^{\circ} \mathrm{C} \mathrm{min}^{-1}$. 

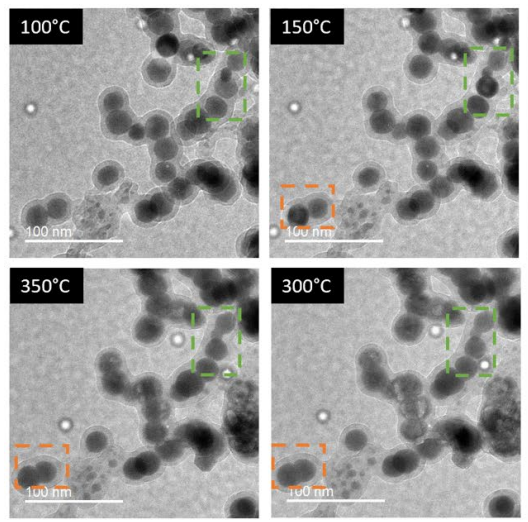
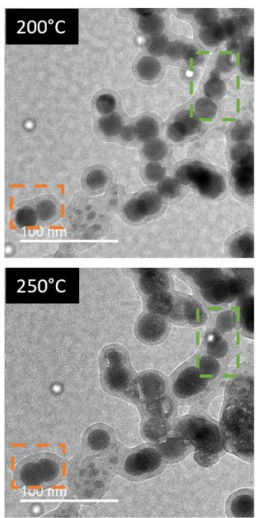
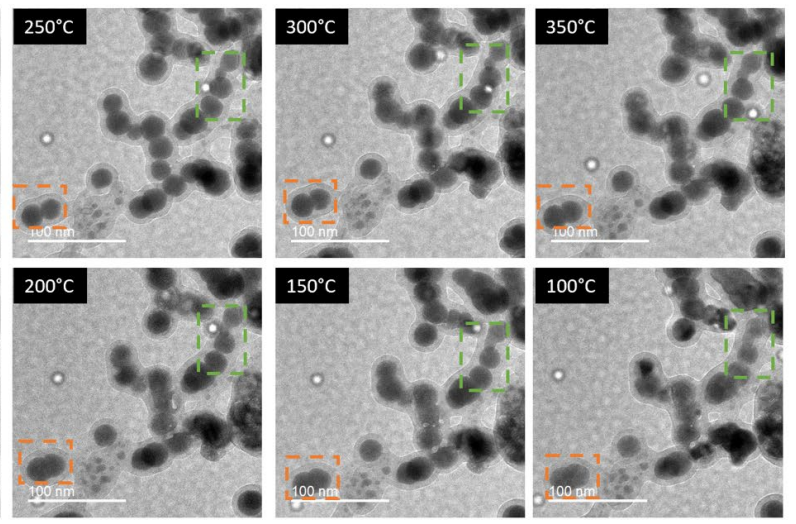

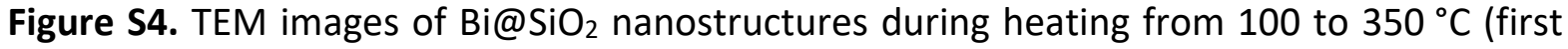
row) and cooling (second row) under 760 Torr of argon at $10^{\circ} \mathrm{C} \mathrm{min}^{-1}$. The samples was preheated at $100{ }^{\circ} \mathrm{C}$ for $2 \mathrm{~h}$. The orange rectangle shows two Bi cores embedded in the same silica shell and coalescing irreversibly. The green rectangle shows $\mathrm{Bi}$ cores that remain separated after cooling.

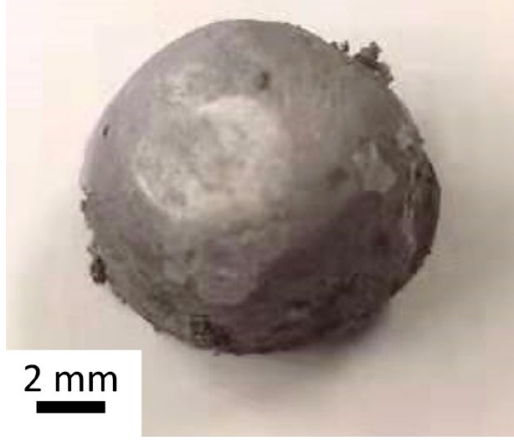

Figure S5. Optical image of $\mathrm{Bi@SiO} 2-\mathrm{Al}$ sample. 


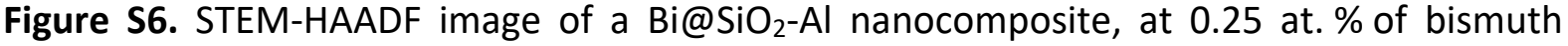
particles. 